\title{
Anomalous Origin of the Vertebral Artery
}

\author{
André Luis Shinohara ${ }^{1}$ Beatriz Sobrinho Sangalette ${ }^{2}$ Mateus José da Silva ${ }^{1}$ Laís Rinaldi ${ }^{1}$ \\ Juliane Ruiz de Souza ${ }^{1}$ Rogério Leone Buchaim ${ }^{1}$ Jesus Carlos Andreo ${ }^{1}$ Sandra Lia do Amaral ${ }^{3}$ \\ Gustavo Lopes Toledo 4
}

${ }^{1}$ Department of Biological Sciences-Anatomy, Faculdade de Odontologia de Bauru, Universidade de Sâo Paulo, Bauru, SP, Brazil

2 Faculdade de Odontologia de Marilia, Universidade de Marilia, Marília, SP, Brasil

${ }^{3}$ Department of Physical Education, Faculdade de Ciências,

Universidade Estadual Paulista, Bauru, SP, Brazil

${ }^{4}$ Department of Oral Maxillofacial Surgery, Faculdade de Odontologia

de Marília, Universidade de Marília, Marília, SP, Brasil

\begin{abstract}
Address for correspondence Beatriz Sobrinho Sangalette, Avenida Waldemar Kireff, 185, apt, 22 - Jardim Araxá, Marília, SP 17525-020, Brazil (e-mail: beatrizsangalett@gmail.com).
\end{abstract}

J Morphol Sci 2018;35:216-217.

\begin{abstract}
Keywords

- anatomic variation

- clinical anatomy

- vertebral artery

Introduction The present article presents a rare case of variation of the left vertebral artery, which originated from the aortic arch, between the common carotid artery and the subclavian artery, although classic descriptions of the vertebral artery indicate its origin at the subclavian artery, where it penetrates the foramen transverse and ascends cervically to the foramen magnum.

Case presentation The anatomical peculiarity of the vertebral artery is evidenced. The origin of the vertebral artery was identified directly from the aortic arch in a dissected human specimen.

Conclusion In view of the numerous surgical procedures performed in this area, the clear understanding of its topographic layout is indispensable, and might change surgical procedures performed in the region.
\end{abstract}

\section{Introduction}

The vertebral artery usually originates from the subclavian artery and ascends superomedially, passing previously by the transverse process of the $\mathrm{C} 7$ vertebra, transposing the transverse foramen to the level of the C6 vertebra, and following a slightly linear course toward the $\mathrm{C} 2$ vertebra. ${ }^{1}$ It travels along the lateral posterior path and, before becoming clearly cephalic, it passes through the transversal foramen of the C1 vertebra. The vertebral artery ascends anteriorly to enter the posterior fossa of the foramen magnum, and then it joins the opposite side, originating the basilar artery of the midline. ${ }^{2}$

One of the most frequent variations refers to the direct origin of the left vertebral artery through the aortic arch, which means that it emerges immediately after the left common carotid and to the right of the subclavian artery of the same side, with an incidence in between 2 and $4 \%$ of the cases. ${ }^{3}$

received

October 14, 2018

accepted

November 8, 2018

10.1055/s-0038-1676779. ISSN 2177-0298.
The anomalous origin of the vertebral artery does not imply functional implications for the patient. However, the diagnosis of this abnormality in cases of vascular diseases, such as arteriovenous malformations or aneurysms, during cerebral angiography, is indispensable so that errors might be avoided during endovascular surgeries in the region of the head and neck, suggesting the relevance of its documentation. ${ }^{4}$

\section{Short Communication}

During the dissection of a male human specimen stored in the biological sciences department of the Faculty of Dentistry of Bauru-at Universidade de São Paulo (FOB-USP, in the Portuguese acronym)- to access the cardiovascular system for didactic purposes, the presence of something uncommon was detected, aortic arch contained the presence of an additional vessel to the classical anatomy.

Copyright @ 2018 by Thieme Revinter

Publicações Ltda, Rio de Janeiro, Brazil

License terms

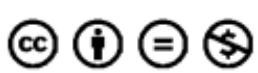


Analyzing the present structures, it was concluded that it was a variation from the left vertebral artery, which originated from the aortic arch, between the common carotid artery and the subclavian artery, although its origin is commonly described in the left subclavian artery (-Figs. 1, 2)

\section{Discussion}

Although the vertebral artery is classically described as the first branch of the subclavian artery, several variations in the origin of the vertebral artery have been reported, such as its emergence from the common carotid artery, and may include duplicate origin from the aortic arch and from the subclavian artery. ${ }^{2,5}$ In agreement with the literature, the present report brings a new singularity of the left vertebral artery, this one deriving from the aortic arch, between the common carotid artery and the subclavian artery.

Nayak et al, analyzing 62 human specimens, observed anatomical variations in $1.6 \%$ of the cases, whose vertebral artery arose from the aortic arch. ${ }^{3}$ Heary et $\mathrm{al}^{5}$ reported that 2.4 to $5.8 \%$ of the cases of alterations occur in the left vertebral artery, arising directly from the aortic arch, between the left common carotid artery and the left subclavian artery, in agreement with the present report ${ }^{5}$.

In the majority of reports, the anomalous origin of the vertebral artery did not result in clinical symptomatology. Although some authors have hypothesized that the origin and anomalous distribution of a large cervical artery may result in cerebral hemodynamic disturbance with secondary cerebral alterations, no conclusive evidence suggest that this fact predisposes an individual to cerebrovascular disorders. ${ }^{4,6}$

In short, the main characteristic of the clarification of the anomalous origin it's in the previous acknowledgement of possible situations that may alter the treatment plan, since in the accomplishment of vascular surgeries of the supra-aortic

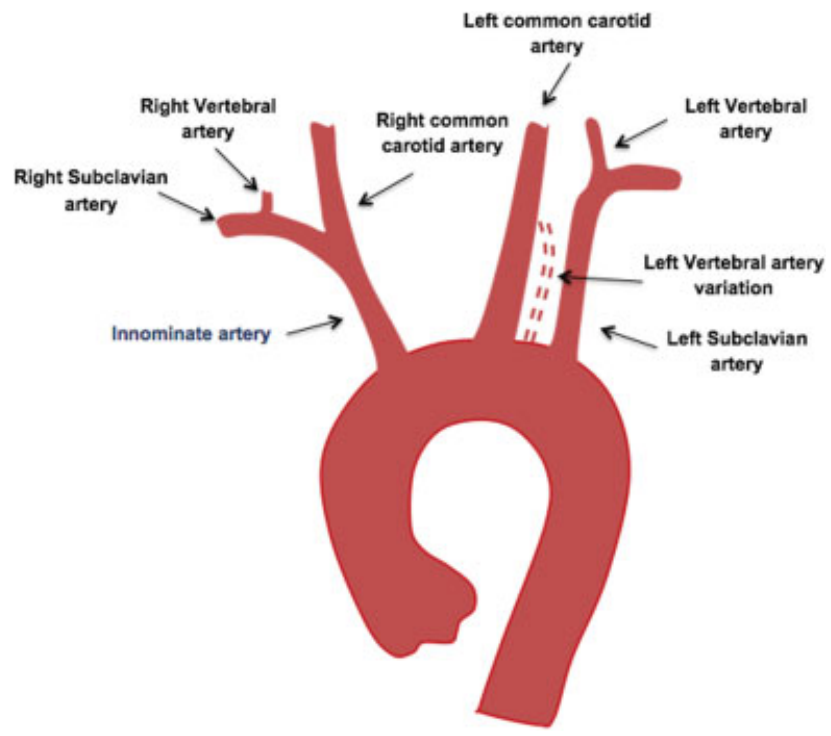

Fig. 1 Normal schematic diagram of the aortic arch and the great vessels demonstrates the anatomic variation of the left vertebral artery arising from the aortic arch, between the common carotid artery and the subclavian artery.

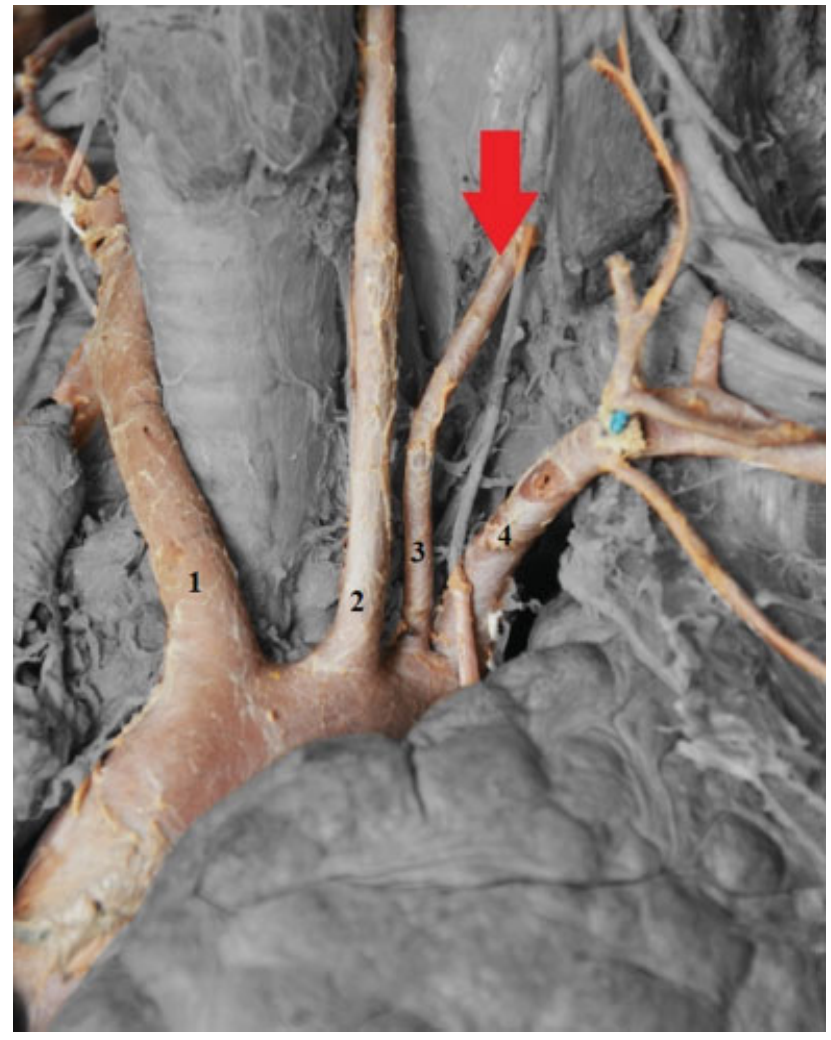

Fig. 2 Aortic arch with the innominate artery (1), left common carotid artery (2), anomalous position of the vertebral artery (3), and the left subclavian artery (4).

arteries, the knowledge of variants of the vertebral artery is essential for the correct planning and execution of the procedure, to avoid trans- and postoperative disorders to the patient.

\section{Conflicts of Interest}

The authors have no conflicts of interest to declare.

\section{Acknowledgments}

For the contribution in the translation and in the revision of the portuguese language into the English language, we thank the language teacher Bruno Oliver and the native speaker Michael Zeigler.

\section{References}

1 Gray H, Williams PL. Bannister, Lawrence H. Gray's Anatomy. 37nd ed. New York: Churchill Livingstone; 1995:312-315

2 Giuffrè R, Sherkat $\mathrm{S}$. The vertebral artery: developmental pathology. J Neurosurg Sci 1999;43(03):175-189

3 Nayak SR, Pai MM, Prabhu LV, et al. Anatomical organization of aortic arch variations in the India: embryological basis and review. J Vasc Bras 2006;5:95-100

4 Goray VB, Joshi AR, Garg A, Merchant S, Yadav B, Maheshwari P. Aortic arch variation: a unique case with anomalous origin of both vertebral arteries as additional branches of the aortic arch distal to left subclavian artery. AJNR Am J Neuroradiol 2005;26(01):93-95

5 Heary RF, Albert TJ, Ludwig SC, et al. Surgical anatomy of the vertebral arteries. Spine 1996;21(18):2074-2080

6 Satti SR, Cerniglia CA, Koenigsberg RA. Cervical vertebral artery variations: an anatomic study. AJNR Am J Neuroradiol 2007;28 (05):976-980 